\title{
Synthetic cannabinoids in the kidneys
}

\author{
Alper Alp ${ }^{1 *}$, Hakan Akdam² ${ }^{2}$ Banu Yilmaz AvcioĞlu ${ }^{1}$, Sibel Ersan $^{1}$ \\ ${ }^{1}$ Nephrology, Tepecik Education and Research Hospital, Izmir, Turkey \\ ${ }^{2}$ Department of Nephrology, School of Medicine, Adnan Menderes University, Aydin, Turkey
}

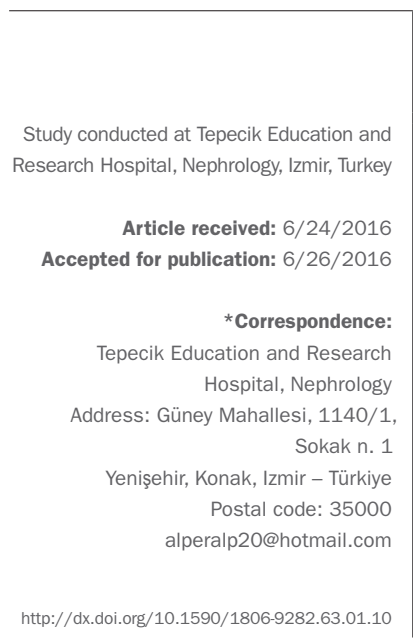

\section{SUMmARY}

Acute kidney injury is an important cause of mortality and morbidity today and can occur due to several reasons. As time, geographic regions, and living conditions change, various etiological agents arise with nephrotoxic effects. Awareness of such nephrotoxic effects has been raised with the increasing frequency of addictive substance use, especially among young people in society.

Keywords: synthetic cannabinoids, acute kidney injury, toxicity.

\section{INTRODUCTION}

Synthetic cannabinoids (SC) are addictive substances with an increasing frequency of use among the young population. It is reported that the rate of synthetic cannabinoid use among United States (US) high school students is approximately 11 to $12 \% .^{1}$ The detection of these substances in plasma and urine samples by toxicology tests has some difficulties because producers frequently change the molecular structure to avoid breaking the law. This "ghost" effect and the relatively cheap price compared with other addictive substances make SCs popular among this population.

These compounds have several psychiatric, metabolic, and physiological effects. In recent years, cases of acute kidney injury (AKI) have appeared due to the use of cannabinoids. Most of these cases show complete improvement without biopsy and, therefore, biopsy findings are known in a very limited number of such cases.

Although the general histopathological finding is consistent with acute tubular necrosis (ATN), there are also cases with detected findings of tubulointerstitial nephritis. It is important to enhance awareness in this regard and also to emphasize the likelihood of developing renal injury in addicted patients.

\section{What aRE SYNTHETIC CANNABINOIDS?}

Synthetic cannabinoids are marijuana-like, non-natural, chemically produced components. Their molecular structure shows much similarity with $\Delta 9$-tetrahydrocannabinol (THC), the main active compound in marijuana. Although they are similar, SCs are more potent molecules. They act like agonists for cannabinoid (CB) receptors. Cannabis-like (mimetic effect) components in SCs affect cell receptors (CB1 and CB2) in the brain, causing an effect 100 times more potent than THC contained in normal marijuana. SCs may not be as "innocent" as marijuana and have more potent and different side effects due to their biochemical differences. Some of these components are HU-210, CP 47, 497, JWH-018, JWH-073, JWH-398, and JWH- 250.

SCs are a group of substances with addictive and psychoactive effects, which is highly popular especially among young people due to its cannabis-like effects. The commercial products are sold under the name " $\mathrm{k} 2$," "spice," and "black mamba" in the US and the European Union $(\mathrm{EU})$, and "Bonsai" and "Jamaica" in Turkey.

Some other well-known products containing SCs are "spice gold," "spice silver," "spice diamond," "silver," "yucatan fire," "sence," "chill X," "smoke,” "gnie,” "algerian blend." The formal reports both from the US and EU indicate that the rate of SC use is growing faster every year. They can cause many health problems, from acute severe crises to several organ dysfunctions (arrhythmia, anxiety, agitation, confusion, hypertension, seizures, hallucinations, AKI, and myocardial infarction) and even death. ${ }^{2}$

\section{SyNTHETIC CANNABINOID-RELATED ACUTE KIDNEY INJURY (SC-RAKI)}

In recent years, renal injury-causing effects of SCs have been encountered, even though they are rare. The most common 
result of renal exposure is AKI. A study from the US found renal injury of approximately $0.9 \%$ due to SC use. ${ }^{3}$

The mechanism of renal injury is not yet clearly defined. ${ }^{4}$ Acute tubular necrosis seems to be the leading etiology for AKI among these patients. However, classical hemodynamic collapse, hypotension or hypovolemic status for development of ATN may not be present. Cardiac effects of SCs are also very well-described. The negative inotropic effects on hemodynamic processes may have impact on renal blood flow decrease. These cardiac effects also may aggravate prerenal conditions. Rhabdomyolysis and cannabinoid hyperemesis syndrome are the second most commonly seen etiologies. ${ }^{5}$ Also, direct toxic effects of the SC molecules or addictive substances during elimination from the kidney may be responsible. Unfortunately, it is not clear which components are responsible for their nephrotoxic effect. Some reports revealed that in particular XLR11 and UR-144 N-pentanoic acid metabolite were detected in the serum and urine samples of the cases with SC-RAKI. ${ }^{6}$ An experimental study of Barutta et al. showed that blockade of CB1 receptors has been shown to have protective effects on renal function and ameliorate albuminuria in diabetic mice. ${ }^{7}$

As we have a look at the literature, obviously, renal biopsy for SC-RAKI is not much preferred. The "prerenal" nature of AKI in these patients might have caused this approach. The renal biopsy applied cases mostly revealed ATN. To a rare extent, tubulointerstitial nephritis and crescentic glomerulonephritis were reported (Table 1).

Additionally, hypokalemia and hypertension may occur during SC use, but less frequently.

\section{Reported etiologies for SC-RAKI}

\section{Cannabinoid hyperemesis syndrome (CHS)}

Cannabis is known for its anti-emetic effects; however, SCs may cause intractable nausea and vomiting. The most common symptoms of the patients at hospital admission are nausea and vomiting due to SC use and those were consistent with ATN in kidney biopsies. This clinical situation is called as cannabinoid hyperemesis syndrome (CHS). Allen et al. described this entity first in $2004 .{ }^{9}$ In some papers "hyperemetic hydrophilic syndrome" is also used as synonym.

This syndrome is more common in chronic users and courses with periodic vomiting (especially in the morning), abdominal pain or discomfort, and the desire for a hot shower. Long-term use of SCs is essential in provoking symptoms. The cyclic pattern of these symptoms is pathognomonic. Prerenal kidney injury may occur secondary to this presentation. ${ }^{10,11}$ Acute tubular necrosis is the most common reason causing renal injury so biopsy may not be indicated if the clinical presentation is as stated..$^{12} \mathrm{~A}$ diagnostic algorithm was described for such patients. ${ }^{13}$ The treatment approaches are palliative. Satisfactory results with haloperidol, intravenous $\mathrm{NaCl} 0.9 \%$, paracetamol, lorazepam, ondansetron, and morphine use are reported in the literature. ${ }^{14,15}$

\section{Rhabdomyolysis}

Rhabdomyolysis was also shown to cause kidney injury in these cases. However, it is not clear whether direct toxic effects of compounds in SCs on muscles are responsible for this entity. Some other side effects of SCs like hypokalemia or hyperthermia may also have contribution. ${ }^{16-18}$ In addition to these two clinical approaches, unfortunately the pathophysiology of cannabinoid-associated renal injury has not been fully clarified. The treatment strategies for SC induced rhabdomyolysis did not differ from classical approaches.

\section{Tubulointerstitial nephritis}

With respect to cannabinoid-associated kidney injury, the literature very rarely contains cases with acute tubulointerstitial nephritis, as well. ${ }^{19}$ Although acute tubulointerstitial nephritis may be directly caused by the effect of SC, various nephrotoxic chemical substances or heavy metals added to these synthetic compounds that have no standardization may also have an effect on such biopsy results. ${ }^{20}$ There are very few reports of the co-existence of SC-RAKI and tubulointerstitial nephritis in the literature. ${ }^{19,21}$ In some cases tubular oxalate crystals accompanying tubulointerstitial nephritis were described. ${ }^{22}$ There is no specific treatment for cannabinoid-associated effects. Support therapy, cardiac monitoring, and follow-up of consciousness and vital signs are essential.

\section{Conclusion}

One of the current, most socially important and growing problems is the increasingly frequent use of synthetic cannabinoids and similar substances, especially among the young population. Addicts using such substances may present not only with central side effects such as psychiatric symptoms, seizure, mania, and changes in consciousness, but also with renal dysfunction. Synthetic substance use should be considered in patients who are young, without any chronic diseases, and with AKI that may present with cognitive and psychiatric symptoms. Failure to identify all components in routine urine toxicological analyses can lead to misdiagnosis. Monitoring kidney function tests is important during the follow-up of patients since SCs have the potential to increase the occurrence of acute kidney injury. 
TABLE 1 Recently reported cases of SC-RAKI (between 2013 and 2016).

\begin{tabular}{|c|c|c|c|c|c|c|c|}
\hline Author & Age & $\begin{array}{l}\text { Peak creatinine } \\
(\mathrm{mg} / \mathrm{dL})\end{array}$ & $\begin{array}{l}\text { Peak creatinine kinase } \\
(U / L)\end{array}$ & RRT & $\begin{array}{l}\text { Renal } \\
\text { biopsy }\end{array}$ & Renal pathology & ESRD \\
\hline Sweeney et al. ${ }^{16}$ & 27 & 2.2 & 57,050 & No & No & Rhabdomyolysis & No \\
\hline Argamany et al. ${ }^{17}$ & 27 & 13.88 & $>40,000$ & No & No & Rhabdomyolysis & No \\
\hline Zhao et al. ${ }^{18}$ & 39 & 9.7 & 148,643 & HD & No & Rhabdomyolysis & No \\
\hline Elçioğlu et al. ${ }^{12}$ & 28 & 6.5 & 191 & No & Yes & Acute tubular necrosis & No \\
\hline Ukaigwe et al. ${ }^{11}$ & 38 & 4.78 & ?? & No & No & Prerenal (CHS) & No \\
\hline Gudsoorkar et al. ${ }^{4}$ & 26 & 8.1 & 2,337 & HD & No & Not specified & No \\
\hline Sherpa et al. ${ }^{5}$ & 45 & 3.06 & 301,901 & CRRT & No & Rhabdomyolysis & No \\
\hline Kamel et al. ${ }^{22}$ & 65 & 5.6 & Normal & HD & Yes & TIN, calcium oxalate crystals & $?$ \\
\hline Kazory et al. ${ }^{21}$ & 22 & 7.05 & 338 & No & Yes & Acute tubular necrosis & No \\
\hline Habboushe et al. ${ }^{23}$ & 26 & 3.21 & Not specified & No & No & $\mathrm{CHS}$ & No \\
\hline Thornton et al. ${ }^{24}$ & 26 & 7.74 & Normal & No & Yes & $\begin{array}{l}\text { Rare globally sclerotic glomeruli, } \\
\text { no evidence } \\
\text { of acute glomerular disease }\end{array}$ & No \\
\hline
\end{tabular}

HD: hemodialysis; CRRT: continuous renal replacement therapy; CHS: cannabinoid hyperemesis syndrome; RRT: renal replacement therapy; TIN: tubulointerstitial nephritis; SC-RAKI: synthetic cannabinoid-related acute kidney injury; ESRD: end-stage renal disease.

\section{Conflict Of INTERest}

The authors declare no conflict of interest.

\section{RefEREnCES}

1. The Partnership for a Drug Free America and the MetLife Foundation, The Partnership Attitude Tracking Study (PATS): Teens and Parents, 2013.

2. Behonick G, Shanks KG, Firchau DJ, Mathur G, Lynch CF, Nashelsky M, et al. Four postmortem case reports with quantitative detection of the synthetic cannabinoid, 5F-PB-22. J Anal Toxicol. 2014; 38(8):559-62.

3. Forrester MB, Kleinschmidt K, Schwarz E, Young A. Synthetic cannabinoid and marijuana exposures reported to poison centers. Hum Exp Toxicol 2012; 31(10):1006-11.

4. Gudsoorkar VS, Perez JA. A new differential diagnosis: synthetic cannabinoidsassociated acute renal failure. Methodist Debakey Cardiovasc J. 2015; 11(3):189-91.

5. Sherpa D, Paudel BM, Subedi BH, Chow RD. Synthetic cannabinoids: the multi-organ failure and metabolic derangements associated with getting high. J Community Hosp Intern Med Perspect. 2015; 5(4):27540.

6. Castaneto MS, Gorelick DA, Desrosiers NA, Hartman RL, Pirard S, Huestis MA. Synthetic cannabinoids: epidemiology, pharmacodynamics and clinical implications. Drug Alcohol Depend. 2014; 144:12-41.

7. Barutta F, Corbelli A, Mastrocola R, Gambino R, Di Marzo V, Pinach S, et al. Cannabinoid receptor 1 blockade ameliorates albuminuria in experimental diabetic nephropathy. Diabetes. 2010; 59(4):1046-54.

8. Hermanns-Clausen M, Kneisel S, Szabo B, Auwärter V. Acute toxicity due to the confirmed consumption of synthetic cannabinoids: clinical and laboratory findings. Addiction. 2013; 108(3):534-44.

9. Allen JH, de Moore GM, Heddle R, Twartz JC. Cannabinoid hyperemesis: cyclical hyperemesis in association with chronic cannabis abuse. Gut 2004 53(11):1566-70.

10. Bhanushali GK, Jain G, Fatima H, Leisch LJ, Leisch LJ, Thornley-Brown D. AKI associated with synthetic cannabinoids: a case series. Clin J Am Soc Nephrol. 2013; 8(4):523-6.
11. Ukaigwe A, Karmacharya P, Donato A. A gut gone to pot: a case of cannabinoid hyperemesis syndrome due to K2, a synthetic cannabinoid. Case Rep Emerg Med. 2014; 2014:167098.

12. Elçioğlu OC, Bașçı S, Bakan A, Aydin Bahat K, Özlük MY, Kiliçaslan I, et al. Synthetic cannabinoids associated acute kidney injury: case report. Turkiye Klinikleri J Nephrol. 2015; 10(2):43-6.

13. Simonetto DA, Oxentenko AS, Herman ML, Szostek JH. Cannabinoid hyperemesis: a case series of 98 patients. Mayo Clinic Proc. 2012; 87(2):114-9.

14. Price SL, Fisher C, Kumar R, Hilgerson A. Cannabinoid hyperemesis syndrome as the underlying cause of intractable nausea and vomiting. J Am Osteopath Assoc. 2010; 111(3):166-9.

15. Hickey JL, Witsil JC, Mycyk MB. Haloperidol for treatment of cannabinoid hyperemesis syndrome. Am J Emerg Med. 2013; 31(6):1003.e5-6.

16. Sweeney B, Talebi S, Toro D, Gonzalez K, Menoscal JP, Shaw R, et al Hyperthermia and severe rhabdomyolysis from synthetic cannabinoids. Am J Emerg Med. 2016; 34(1):121.e1-2.

17. Argamany JR, Reveles KR, Duhon B. Synthetic cannabinoid hyperemesis resulting in rhabdomyolysis and acute renal failure. Am J Emerg Med. 2016; 34(4):765.e1-2.

18. Zhao A, Tan M, Maung A, Salifu M, Mallappallil M. Rhabdomyolysis and acute kidney injury requiring dialysis as a result of concomitant use of atypical neuroleptics and synthetic cannabinoids. Case Rep Nephrol. 2015; 2015:35982.

19. Centers for Disease Control and Prevention (CDC). Acute kidney injury associated with synthetic cannabinoid use - Multiple states, 2012. MMWR Morb Mortal Wkly Rep. 2013; 62(6):93-8.

20. Wells DL, Ott CA. The "new" marijuana. Ann Pharmacother. 2011; 45(3):414-7.

21. Kazory A, Aiyer R. Synthetic marijuana and acute kidney injury: an unforeseen association. Clin Kidney J. 2013; 6(3):330-3.

22. Kamel M, Thajudeen B. A case of acute kidney injury and calcium oxalate deposition associated with synthetic cannabinoids. Saudi J Kidney Dis Transpl. 2015; 26(4):802-3.

23. Habboushe J, Sedor J. Cannabinoid hyperemesis acute renal failure: a common sequela of cannabinoid hyperemesis syndrome. Am J Emerg Med. 2014; 32(6):690.e1-2.

24. Thornton SL, Wood C, Friesen MW, Gerona RR. Synthetic cannabinoid use associated with acute kidney injury. Clin Toxicol (Phila). 2013; 51(3):189-90. 